\title{
Seasonal origins of soil water used by trees
}

\author{
Scott T. Allen ${ }^{1,2}$, James W. Kirchner ${ }^{1,3,4}$, Sabine Braun ${ }^{5}$, Rolf T. W. Siegwolf ${ }^{2,3}$, and Gregory R. Goldsmith ${ }^{2,6}$ \\ ${ }^{1}$ Department of Environmental Systems Science, ETH Zurich, Zurich, 8092, Switzerland \\ ${ }^{2}$ Ecosystem Fluxes Group, Laboratory for Atmospheric Chemistry, Paul Scherrer Institute, Villigen, 5232, Switzerland \\ ${ }^{3}$ Swiss Federal Research Institute WSL, Birmensdorf, 8903, Switzerland \\ ${ }^{4}$ Department of Earth and Planetary Science, University of California, Berkeley, CA, USA \\ ${ }^{5}$ Institute for Applied Plant Biology, Witterswil, 4108, Switzerland \\ ${ }^{6}$ Schmid College of Science and Technology, Chapman University, Orange, CA 92866, USA
}

Correspondence: Scott T. Allen (allensc@ethz.ch)

Received: 1 November 2018 - Discussion started: 5 November 2018

Revised: 11 February 2019 - Accepted: 21 February 2019 - Published: 1 March 2019

\begin{abstract}
Rain recharges soil water storages and either percolates downward into aquifers and streams or is returned to the atmosphere through evapotranspiration. Although it is commonly assumed that summer rainfall recharges plantavailable water during the growing season, the seasonal origins of water used by plants have not been systematically explored. We characterize the seasonal origins of waters in soils and trees by comparing their midsummer isotopic signatures $\left(\delta^{2} \mathrm{H}\right)$ to seasonal isotopic cycles in precipitation, using a new seasonal origin index. Across 182 Swiss forest sites, xylem water isotopic signatures show that summer rain was not the predominant water source for midsummer transpiration in any of the three sampled tree species. Beech and oak mostly used winter precipitation, whereas spruce used water of more diverse seasonal origins. Even in the same plots, beech consistently used more winter precipitation than spruce, demonstrating consistent niche partitioning in the rhizosphere. All three species' xylem water isotopes indicate that trees used more winter precipitation in drier regions, potentially mitigating their vulnerability to summer droughts. The widespread occurrence of winter isotopic signatures in midsummer xylem implies that growing-season rainfall may have minimally recharged the soil water storages that supply tree growth, even across diverse humid climates (690$2068 \mathrm{~mm}$ annual precipitation). These results challenge common assumptions concerning how water flows through soils and is accessed by trees. Beyond these ecological and hydrological implications, our findings also imply that stable isotopes of $\delta^{18} \mathrm{O}$ and $\delta^{2} \mathrm{H}$ in plant tissues, which are often
\end{abstract}

used in climate reconstructions, may not reflect water from growing-season climates.

\section{Introduction}

Plant water availability shapes ecosystems, climates, and natural resources. In hydrology and ecology, soil water storage is often represented as a bucket or vertical stack of wellmixed reservoirs, filled by previous precipitation events, and used by plants as a function of their rooting depth (Lawrence, et al., 2011; Wigmosta et al., 1994). The reality is more complex: water transport through soils tends to be dominated by preferential flow through large pores, whereas water is often primarily stored in the finer matrix (Beven and Germann, 1982; Lawes et al., 1882). Thus, plant water availability depends on the interplay between macropore flow, matrix storage, and the rooting architecture of vegetation (Brooks et al., 2010; Stewart et al., 1999; Tinker, 1976). Previous research has documented depths of roots and root water uptake (Dubbert et al., 2019; Fan et al., 2017; West et al., 2012), but little attention has been directed towards understanding how water becomes available for uptake at those depths.

Water stable isotope signatures $\left(\delta^{2} \mathrm{H}\right.$ and $\left.\delta^{18} \mathrm{O}\right)$ have been used as tracers to show that plant water uptake is not sourced from the same subsurface storage as streamflow (Evaristo et al., 2015; Good et al., 2015; Javaux et al., 2016), but it remains unclear how that storage is replenished and becomes available to plants. Soils may retain a mixture of waters that originate from many previous precipitation events (Botter 
et al., 2011; Mueller et al., 2014; Sprenger et al., 2016b; Brinkmann et al., 2018), but plants may not evenly sample from that distribution of water ages, because plants may root such that they preferentially take up water moving along faster or slower pathways (Brooks et al., 2010; Ehleringer et al., 1991; Stewart et al., 1999). These interactions between root distributions and infiltration dynamics could hypothetically result in plants disproportionally using precipitation from past seasons rather than recent precipitation. While a few case studies have reported plants predominantly using precipitation from past seasons in arid (Ehleringer et al., 1991) or Mediterranean climates (Brooks et al., 2010; Rempe and Dietrich, 2018) where there is minimal growing-season precipitation, the seasonal origins of water used by plants have not been systematically explored in humid climates.

To investigate the seasonal origins of waters that supply midsummer tree growth, we analyzed xylem water isotopes from a snapshot sample of 918 trees from three dominant species in 182 forest sites across Switzerland. At 31 of these sites, we complemented the xylem water with isotope values of soil waters, sampled using suction lysimeters (which are generally considered to access the more mobile fraction of soil waters that are not held under high tensions; Brooks et al., 2010). To characterize the seasonal origins of xylem water and lysimeter soil water, we developed a seasonal origin index, based on the isotopic signature of soil and plant water relative to the seasonal precipitation isotope cycle; this index quantifies the overexpression of winter versus summer (recent) precipitation in xylem or lysimeter waters, relative to annual precipitation. This new seasonal origin index can be effectively used in these sites because the strong seasonal isotopic cycle in Swiss precipitation (Allen et al., 2018) allows for winter and summer precipitation to be clearly distinguished in tree xylem. We used this midsummer snapshot to determine (a) whether summer or winter precipitation was overrepresented in midsummer soil and xylem waters, relative to annual precipitation; (b) how the seasonal origins of xylem water varied across diverse climates and site characteristics; and (c) whether these three dominant trees species differed in their water sources.

\section{Materials and methods}

\subsection{The seasonal origin index}

To characterize when xylem water and lysimeter soil water originated as precipitation, we developed a seasonal origin index (SOI),

$$
\mathrm{SOI}=\left\{\begin{array}{ll}
\frac{\delta_{x}-\delta_{\mathrm{annP}}}{\delta_{\text {summerP }}-\delta_{\mathrm{annP}}}, & \text { if } \delta_{x}>\delta_{\mathrm{annP}} \\
\frac{\delta_{\mathrm{x}}-\delta_{\mathrm{annP}}}{\delta_{\mathrm{annP}}-\delta_{\text {winterP }}}, & \text { if } \delta_{x}<\delta_{\mathrm{annP}}
\end{array},\right.
$$

where $\delta_{x}$ is the fractionation-compensated $\delta^{2} \mathrm{H}$ isotopic signature of xylem water or lysimeter soil water, and $\delta_{\text {winterP }}$, $\delta_{\text {summerP }}$, and $\delta_{\mathrm{annP}}$ are the $\delta^{2} \mathrm{H}$ isotopic signatures of typical winter, typical summer, and volume-weighted annual precipitation at each study site (see Sect. 2.4 and Fig. 1). This index expresses the isotopic signature of soil and plant water relative to seasonal precipitation isotope cycles, which are especially strong in high-latitude, continental interiors, where precipitation isotopes are heavy in summer and light in winter (Halder et al., 2015; Vachon et al., 2007). The SOI will be near -1.0 for soil and plant water samples derived entirely from winter precipitation and near 1.0 for samples derived entirely from summer precipitation (Fig. 1). Samples with SOI values near zero approximate the annual average precipitation and can potentially represent many possible mixtures of waters from spring, summer, autumn, and winter. By extracting waters from tree xylem, which reflect the waters taken up by roots (Newberry et al., 2017), and comparing those data to precipitation isotopes, this metric is robust to several uncertainties that are prevalent in isotope-based rooting depth studies, such as sampling and extracting soil waters that are representative of the waters accessed by roots, as described below in greater detail (Goldsmith et al., 2019; Orlowski et al., 2018; Penna et al., 2018).

In using this SOI, we implicitly test the null hypothesis that xylem and lysimeter soil water are the annual volumeweighted average of precipitation, and thus we center the SOI index such that $\mathrm{SOI}=0$ at that value, in any precipitation regime (Fig. 1). We address the following question: is winter or summer water overrepresented in soils or xylem, relative to volume-weighted precipitation? Importantly, this SOI equation (Eq. 1) differs from a simple, two-end-member $\left(\delta_{\text {winterP }}\right.$ and $\left.\delta_{\text {summerP }}\right)$ mixing model, which addresses a different question - is there more winter water than summer water in soils or xylem? - but does not account for the fact that we should expect more winter precipitation in soils (for example) at sites with more winter rainfall. Thus the piecewise linear equation that we use to define $\mathrm{SOI}$ is more appropriate for determining whether winter or summer water is overrepresented in soils and xylem (relative to precipitation inputs) across sites with different seasonal patterns in precipitation; nonetheless, the two approaches yield similar values in areas with relatively even precipitation throughout the year, such as Switzerland (Fig. S1).

\subsection{Field sites and measurements}

The study was carried out in summer of 2015 at 182 sites established across Switzerland as part of a forest health monitoring program (Braun et al., 1999, 2017). Each site contained at least one of three tree species: 97 contained beech (Fagus sylvatica L.), 71 contained spruce (Picea abies (L.) H. Karst.), and 49 contained oak (Quercus robur L.). Sites ranged from 255 to $1840 \mathrm{~m}$ a.s.l. in elevation, 3.3 to $11.1^{\circ} \mathrm{C}$ in mean annual temperature, and 690 to $2068 \mathrm{~mm}$ in to- 


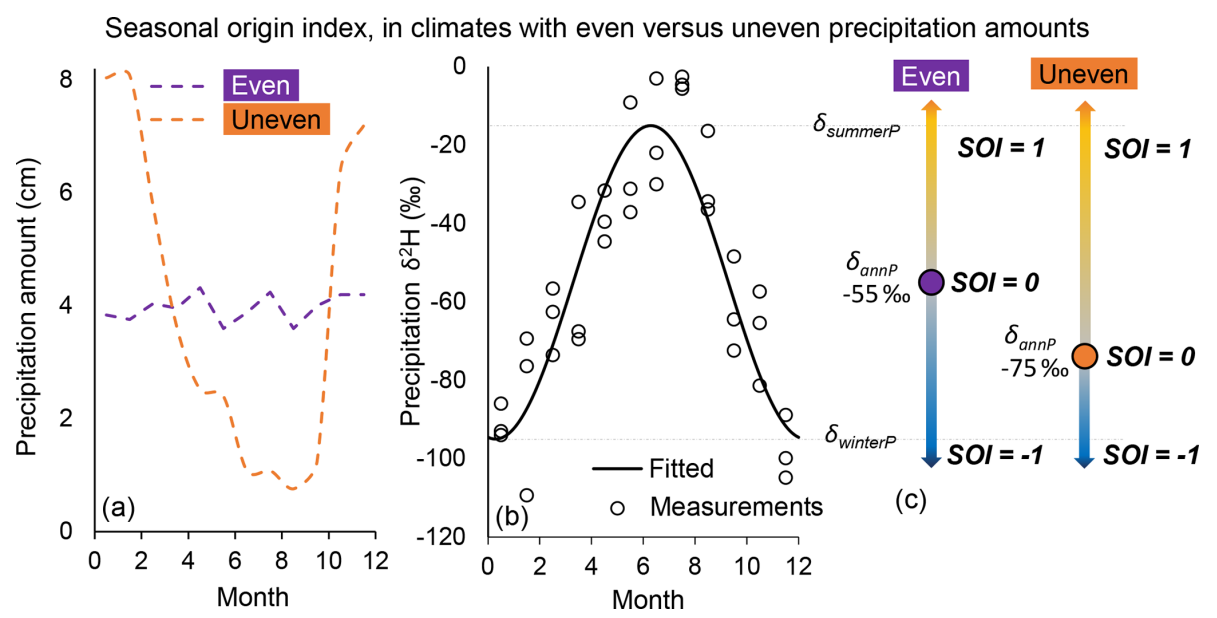

Figure 1. Calculation of the seasonal origin index (SOI). As a hypothetical example, consider one site that receives equal precipitation amounts throughout the year and another site that receives more precipitation in winter (a), but both have the same seasonal isotopic cycle (b). In this example, the volume-weighted average precipitation is $-75 \% \circ \delta^{2} \mathrm{H}$ in the uneven-precipitation site and $-55 \% \circ \delta^{2} \mathrm{H}$ in the evenprecipitation site $(\mathbf{c})$; these values mark SOI $=0$. Thus, if water with $-60 \%$ o $\delta^{2} \mathrm{H}$ was observed in xylem in the uneven-precipitation site, SOI would be positive, indicating that each millimeter of rain that fell during the summer made a larger contribution to xylem water than each millimeter of rain that fell during the winter (even though, owing to the greater precipitation in winter, winter precipitation made up more than $50 \%$ of the xylem water). Panel (b) also shows how the seasonal precipitation isotope cycle is defined by a fitted sinusoid, such that the amplitude captures typical summer and winter peaks and not the absolute bounds of possible values (i.e., SOI of soil or xylem water can be higher than 1.0 or lower than -1.0 ).

tal annual precipitation. The mean elevations of sites with oak (513 $\mathrm{m}$ a.s.1.) and beech (617 $\mathrm{m}$ a.s.l.) were slightly lower than those of sites with spruce ( $893 \mathrm{ma.s.1.).} \mathrm{On} \mathrm{average,}$ mean annual precipitation at sites with oak $\left(1085 \mathrm{~mm} \mathrm{yr}^{-1}\right)$ was slightly lower than at sites with beech $\left(1285 \mathrm{~mm} \mathrm{yr}^{-1}\right)$ or spruce $\left(1339 \mathrm{~mm} \mathrm{yr}^{-1}\right)$. Tree diameters, measured in 2014 , ranged from 17 to $105 \mathrm{~cm}$. All stands are actively managed and composed of mature trees in established, closed-canopy stands. Soils are highly variable in depth (ranging from 30 to $220 \mathrm{~cm}$ ) and texture (ranging from $4 \%$ to $61 \%$ clays and $6 \%$ to $81 \%$ sands in the top $50 \mathrm{~cm}$ ) across the sites (see Figs. S2 and S3). These soils have traits, profiles, and parent materials (documented in the Supplement) that result in them spanning many types and orders, but analyzing those classifications goes beyond the scope of this paper.

To determine the $\delta^{18} \mathrm{O}$ and $\delta^{2} \mathrm{H}$ ratios of xylem water in trees, branches were sampled from 3 to 8 individual trees of each of the species present in each plot. All branch samples were collected between 27 July and 10 August 2015, using pole pruners operated by technicians suspended below helicopters. Thus, all sampled trees occupied at least intermediate canopy positions. On the ground, bark and phloem tissue was removed from fully suberized branches, and samples were sealed in vials and frozen for later extraction and isotopic analysis.

We also determine the $\delta^{18} \mathrm{O}$ and $\delta^{2} \mathrm{H}$ ratios of soil waters accessed by suction lysimeters, which tend to sample a more mobile fraction of soil water (i.e., in contrast to water under high tension or in tight, low-conductivity pore spaces). These lysimeter soil water samples were collected using porous suction cups (Soilmoisture Equipment Corp., Santa Barbara, USA) at 31 of the forest monitoring sites in July 2015. A tension of $60-70 \mathrm{kPa}$ was applied to each suction lysimeter once, within 1 month prior to the xylem sample collection date. Water samples were collected from lysimeters where water could be extracted (i.e., a tension could be applied without losing suction), approximately 4 to 5 weeks after the tension was applied. This so-called "continuous mode" operation is considered to sample flowing waters (Weihermüller et al., 2005), although the actual extraction interval of these lysimeters was likely much shorter than the entire 4 to 5 weeks. Each site had sets of suction lysimeters at one to four different depths (often at 20,50, and $80 \mathrm{~cm}$, but up to $120 \mathrm{~cm}$ deep; see Fig. S2) depending on the soil thickness. For each depth and at each of the 31 sites, there were three to eight replicate lysimeter sets (mean of 6.7). Replicate samples were pooled by depth, then sealed and frozen in $50 \mathrm{~mL}$ vials for later isotopic analysis. We used these lysimeter data to understand the seasonal origins of the more mobile fractions of water in soils (Brooks et al., 2010; Sprenger et al., 2016a), and we do not assume that they are representative of the entire soil water pool, or the pool of water available to plants. While the applied tensions act on all pores, we assume these samples to be more sourced from pores that can conduct water more quickly to a lysimeter, although there is not an explicit pore-size threshold (sensu Grossmann and Udluft, 1991). 
To determine how the $\delta^{18} \mathrm{O}$ and $\delta^{2} \mathrm{H}$ ratios of xylem water and lysimeter soil water varied as a function of soils and climate, additional site metrics were measured. Soil texture (sand, silt, clay, stone, and organic matter content) and fine root density by horizon (including $\mathrm{O}$ horizons) were determined from a soil pit excavated at each site to characterize soil properties. Measurement protocols were consistent with the German soil survey (German BGR, 2005). Elevation was determined for each site from a digital elevation model (25 m resolution; Swiss Federal Office of Topography, Wabern, Switzerland). Slope and aspect were surveyed at each field site, using a compass and clinometer. Mean temperature, precipitation amount, and potential evapotranspiration (PET) were determined using a geospatial model (Meteotest, Bern, Switzerland) based on weather station data. To interpret the fine root density indices assigned to each soil horizon, we converted the ordinal density indices assigned in the field soil survey (W1, W2, W3, W4, W5, W6; German BGR, 2005) to the respective mean values of the index categories $\left(1.5,4,8,15.5,35.5\right.$, and 50 roots $\left.\mathrm{cm}^{-2}\right)$; the density-weighted mean fine root depth (i.e., depth to center of mass) was then calculated using those values for each site. The root profiles, showing density by horizon, are provided in Fig. 2. The Supplement includes taxonomic characterizations of the horizons (from which soil types can be inferred) and by-horizon data on soil textures and root densities.

\subsection{Sample processing and laboratory analyses}

Water was extracted from branch xylem material by cryogenic vacuum distillation (West et al., 2006) at the Paul Scherrer Institute (Villigen, Switzerland). All samples were heated for $2 \mathrm{~h}$ to ensure complete extraction. The $\delta^{18} \mathrm{O}$ and $\delta^{2} \mathrm{H}$ ratios of soil and xylem water were subsequently analyzed using a high-temperature-conversion elemental analyzer (TC/EA) connected to a Delta Plus XP isotope ratio mass spectrometer via a Conflo III interface (Thermo Fisher Scientific, Bremen, Germany). Isotope ratios are expressed in per mil (\%o) notation relative to V-SMOW (Vienna Standard Mean Ocean Water). The long-term instrument precision, measured using independent quality control standards, is $\leq 0.4 \%$ ofor $\delta^{2} \mathrm{H}$ and $\leq 0.2 \%$ for $\delta^{18} \mathrm{O}$. There has been considerable debate over cryogenic vacuum extraction because studies have observed discrepancies in cryogenic extraction of soil water in rehydration experiments (Meißner et al., 2014; Oerter et al., 2014; Orlowski et al., 2018); however, soil waters were not cryogenically extracted in this study, and those discrepancies are not observed when extracting xylem water (Newberry et al., 2017). Physicochemical fractionation processes can occur prior to sampling within plants or at the soil-root interface in xerophytic or halophytic woody plants (Ellsworth and Williams, 2007; Zhao et al., 2016), or at the time of initial leaf flush (Treydte et al., 2014), but the effects of those processes are irrelevant to our midsummer sampling in a humid climate region.

\subsection{Data processing and application in seasonal origin index analysis}

To compare tree xylem water with precipitation inputs at the respective sites, seasonal cycles of the $\delta^{18} \mathrm{O}$ and $\delta^{2} \mathrm{H}$ of precipitation were modeled for each site using a sinusoidal isoscape approach (Allen et al., 2018). Monthly precipitation isotope data were downloaded from 31 monitoring locations in Switzerland (NAQUA network), Austria (Austrian Network of Isotopes in Precipitation), and Germany (Global Network of Isotopes in Precipitation, GNIP); 13 were in Switzerland, and the remaining 18 were within $135 \mathrm{~km}$ of the Swiss border. Sine functions were fitted to precipitation stable isotope measurements at each monitoring site using all available data from 2007 through 2015. Parameters describing the $\delta^{18} \mathrm{O}$ and $\delta^{2} \mathrm{H}$ sine functions (offset, amplitude, phase) were then interpolated across Switzerland by multiple linear regression models using site latitude, longitude, elevation, mean annual temperature range, and mean total precipitation amount as the predictors. This yielded a measure of central tendency (offset) and strength of seasonal cycle (amplitude) for $\delta^{18} \mathrm{O}$ and $\delta^{2} \mathrm{H}$. For each site, we calculated a typical winter precipitation value $\left(\delta_{\text {winterP }}=\right.$ offset - amplitude $)$ and a typical summer precipitation value $\left(\delta_{\text {summerP }}=\right.$ offset + amplitude). The widths of the shaded areas in Figs. 2 and S5 show $\delta_{\text {winterP }}$ and $\delta_{\text {summerp }} \pm 2 \times$ RMSE, where RMSE is the root mean square error of predicted versus fitted amplitude at the precipitation isotope monitoring sites.

To calculate $\delta_{\text {annP }}$ (Eq. 1), we used the volume-weighted mean precipitation of a 24-month period prior to the xylem water field sampling campaign (August 2013-July 2015). Monthly values of precipitation $\delta^{18} \mathrm{O}$ and $\delta^{2} \mathrm{H}$ at each field site were calculated by individual-month multiple linear regression models, fitted to monthly precipitation isotope measurements at the 31 precipitation isotope monitoring sites, using site latitude, longitude, elevation, mean annual temperature range, and mean total precipitation amount as predictors (Allen et al., 2018). In an additional step to account for variations not captured by the regression model, we kriged the prediction residuals of the regression model at each precipitation monitoring station, to create monthly adjustment layers that were added to the regression predictions (Allen et al., 2018). The mean absolute error in predicting monthly precipitation was $1.2 \% \circ \delta^{18} \mathrm{O}$ and $9.6 \% \circ \delta^{2} \mathrm{H}$. Lastly, the sitespecific precipitation isotope values were weighted by sitespecific monthly precipitation amounts (Meteotest, Bern, Switzerland) and summed for the 24 months prior to sampling.

To calculate the seasonal origin index, we used fractionation-compensated lysimeter and xylem water isotope values as approximations of their source values prior to any evaporative fractionation. Deviations of soil or xylem water isotope values from local meteoric water lines (LMWLs) were treated as fractionation effects. To compensate for these fractionation effects, soil or xylem iso- 


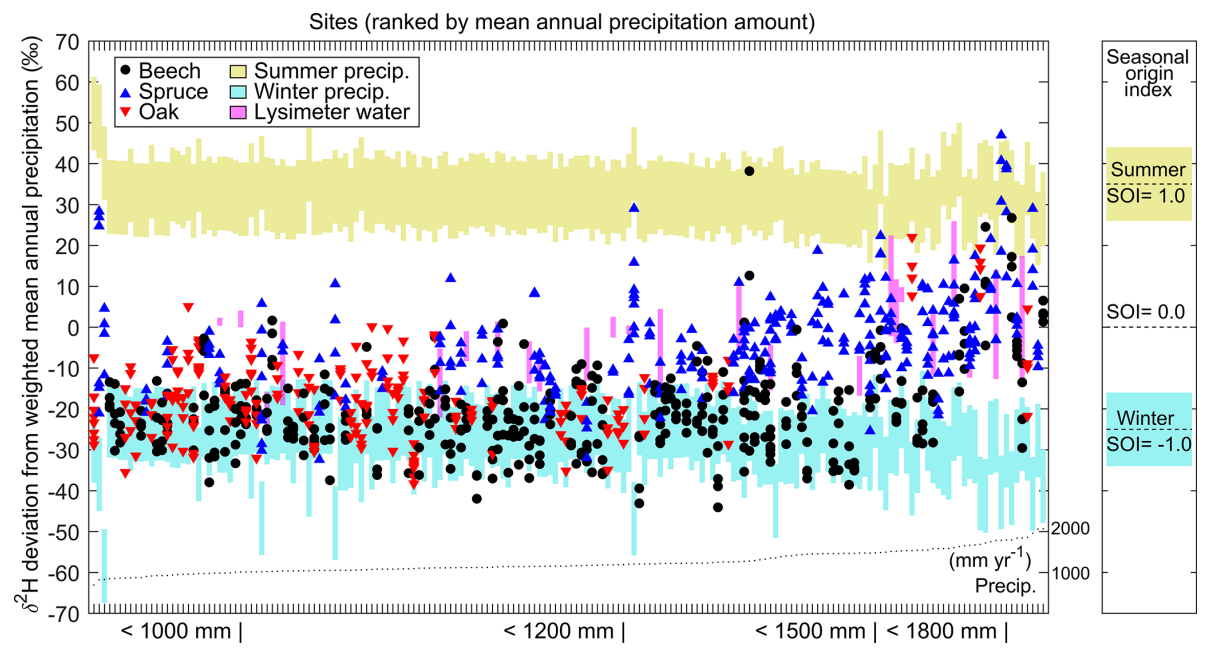

Figure 2. Isotope ratios of xylem water and lysimeter soil water, compared to site-specific seasonal isotope cycles in precipitation. Fractionation-compensated isotope ratios for xylem and soil lysimeter water are plotted as deviations from each site's volume-weighted annual precipitation $\delta^{2} \mathrm{H}$ for the two years prior to the summer 2015 sampling. Typical isotope values for summer and winter precipitation are shaded (see methods). Magenta bars show the $\delta^{2} \mathrm{H}$ range of lysimeter soil water in depth profiles. Sites are ranked by mean annual precipitation amount (see dotted black line and labels below the horizontal axis). The panel on the right depicts how isotope values translate to seasonal origin index values. Trees in all but the wettest sites mostly use water that isotopically resembles winter precipitation (i.e., negative SOI).

tope values were adjusted back to their respective LMWLs along an evaporation line slope, calculated using the CraigGordon model as implemented for diffusion-controlled soil evaporation scenarios by Benettin et al. (2018). Two recent studies have shown that such theory-based approaches are more robust than evaporation lines fitted to soil water observations, which will typically be confounded by isotopic variations in precipitation over time (Benettin et al., 2018; Bowen et al., 2018). Here, we computed the evaporation line at each site as a function of summer mean relative humidity and temperature (Fig. S5). Slopes were calculated using both daily maximum temperatures and daily minimum temperatures to understand the uncertainty associated with the range of conditions under which evaporation occurs; for fractionation compensation, we used the mean of the minimum and maximum temperature slopes. Calculated fractionation slopes across the Swiss sites were between 2.7 and 3.4 (see Fig. S5), consistent with those reported in a previous synthesis (Sprenger et al., 2016a). To compensate for the fractionation effects in xylem water and lysimeter soil water, the monthly precipitation $\delta^{18} \mathrm{O}$ and $\delta^{2} \mathrm{H}$ calculated above for each site were fitted by orthogonal least squares to generate site-specific LMWLs. Then, lysimeter and xylem water values were compensated for evaporative fractionation by shifting them along the site-specific evaporation slopes estimated above until they intersected the LMWLs. These intersection points are the fractionation-compensated values used to represent the precipitation sources of waters in trees and soils (i.e., they were used as the $\delta_{x}$ inputs for the calculation of SOI by Eq. 1). The effects of this fractionation-compensation step can be seen by comparing the patterns and species differences in Figs. 2 and S5.

\subsection{Statistical analyses}

To determine how the $\delta^{18} \mathrm{O}$ and $\delta^{2} \mathrm{H}$ ratios of water in soil and plants varied with soil properties, topography, and climate, we calculated Spearman (rank) correlation coefficients and Pearson (in Table S1 only) correlation coefficients between site characteristics and both xylem SOI and lysimeter SOI. Site-mean SOI was calculated for each species and for shallow $(\leq 30 \mathrm{~cm})$ and deep $(>30 \mathrm{~cm})$ lysimeters. To account for the influence of spatial clustering in correlations, the influence of any given point was weighted by $N^{-1}$, where $N$, calculated by site and by species, is the number of sites within $10 \mathrm{~km}$ that contain the same species; $N$ was also calculated for lysimeters. Details on the site characteristics that we examined are provided in Table S1. A stepwise multiple regression test was also performed to consider interactions between these terms (Table S2). All statistical tests were performed in MATLAB (Mathworks, Inc., Natick, MA, USA).

\section{Results and discussion}

Tree use of winter-sourced water in midsummer was widespread among our 182 Swiss forest sites (Fig. 2). Low (i.e., winter) SOI values were also markedly more prevalent in xylem water than in lysimeter samples of soil water (Fig. 2). Overall, summer (recent) precipitation signatures were uncommon in these midsummer samples; SOI was 


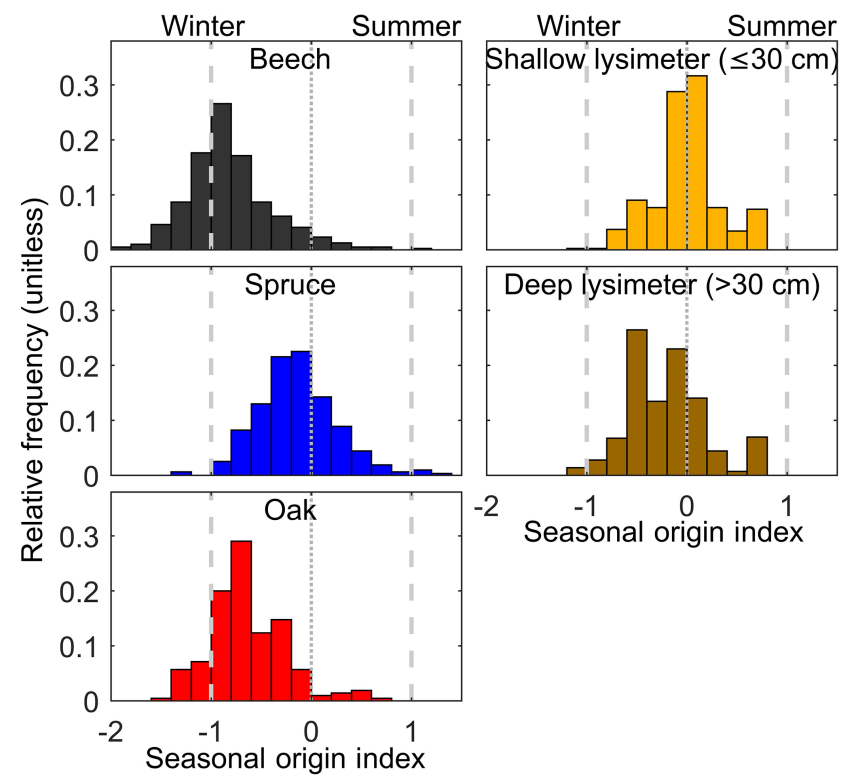

Figure 3. Distributions of the seasonal origin of water in soils and trees across Switzerland in midsummer. Beech and oak xylem show a predominance of winter precipitation. Soil porewaters (sampled by suction lysimeters) and spruce xylem indicate mixtures of precipitation from multiple seasons. Seasonal origin index values below 1 reflect waters that are more isotopically negative than typical winter precipitation (estimated by sinusoidal fitting of precipitation patterns; see Sect. 2).

$>0.5$ for only $1 \%$ of oak and beech samples, $5 \%$ of spruce samples, and $5 \%$ of lysimeter soil water samples (Fig. 3). Winter precipitation signatures were distinctly more common, particularly in the broadleaf trees (oak and beech); SOI was $<-0.5$ for $78 \%$ of oak and beech samples, $17 \%$ of spruce samples, and $19 \%$ of lysimeter soil water samples. Thus, the seasonal origin of the broadleaf tree water was distinctly out of phase with the precipitation at the time of sampling (27 July to 7 August).

The occurrence of winter precipitation in xylem and soils cannot be simply explained by its carryover in snowpacks or by a lack of summer precipitation. Beech and oak, which used more winter precipitation than spruce, occupied lowerelevation (and thus less snowy) sites. Furthermore, for each species, trees in cooler, snowier sites used less winter precipitation (see SOI correlations with temperature and snow fraction in Table 1). Precipitation amounts in Switzerland are distributed relatively evenly throughout the year (Fig. S1), with approximately $58 \%$ of annual precipitation falling in warmer months (Fig. S1). This was also true of 2015, when the sampling occurred, despite that summer having slightly less precipitation than normal (Fig. S1). The average site received $125 \mathrm{~mm}$ (and the driest site received $55 \mathrm{~mm}$ ) of rain in the 50 days prior to sampling (Fig. S1). Even if the fractional volumetric field capacity were 0.35 (O'Green, 2012) and infiltration occurred as piston flow, such that summer precip-

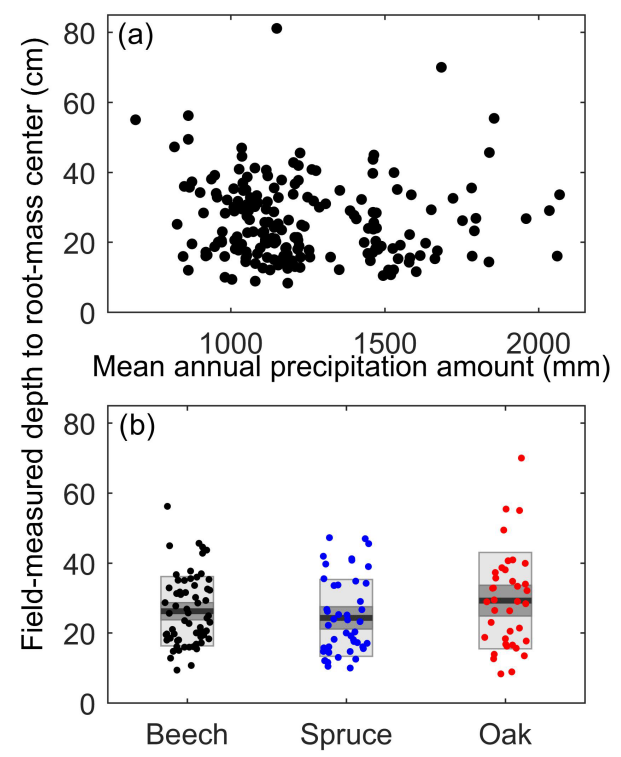

Figure 4. Field-measured fine root depths (a) versus site mean annual precipitation amount and (b) by species for single-species plots. Depth to root-mass center is the mean rooting depth weighted by density of roots per horizon. (a) Its variations were not linearly related to mean annual precipitation $\left(R^{2}<0.01, p=0.40\right)$. (b) The box plots show means (black line) \pm 1 standard error (medium gray), and \pm 1 standard deviation (light gray), of maximum (c) and mean (e) root depths, for the stands that only contained one of the study species; the data suggest that the three species have similar average rooting depths across the sampled sites. See Fig. S2 for more detailed figures on soil and root depths. These metrics refer to fine roots (see methods)

itation displaced previously stored waters (both conservative assumptions), $125 \mathrm{~mm}$ of summer precipitation would have reached depths of $36 \mathrm{~cm}$ (not accounting for evaporation losses). In natural soils, however, infiltrating waters must percolate deeper than they would by piston flow if they mix with previously stored soil moisture or partially bypass the matrix by traveling through macropores (Beven and Germann, 1982; Brooks et al., 2010; Mueller et al., 2014; Sprenger et al., 2016b). Thus, summer precipitation could have reached the depths that contained most of the fine roots (i.e., most roots occur above depths of $15-40 \mathrm{~cm}$, depending on the site; Fig. 4 and Fig. S2). However, only in the wettest sites did summer precipitation predominantly contribute to tree xylem water (Fig. 2). While winter isotopic signatures have previously been observed in summer xylem of desert plants (Ehleringer et al., 1991), our work demonstrates the widespread use of winter water in midsummer across diverse humid climates, prompting the question of how much does tree water use depends on summer rainfall.

The study sites (a) share similar ecological communities and forest management histories and (b) were sampled by a single field crew over a period of just 12 days, thereby minimizing sampling inconsistencies and facilitating compar- 
Table 1. Spearman (rank) correlations between site characteristics and xylem water and lysimeter soil water SOI, where statistically significant correlations are indicated with bold fonts $(p<0.05)$ and bold italic fonts $(p<0.01)$; see Table S1 for a more extensive correlation table.

\begin{tabular}{|c|c|c|c|c|c|}
\hline characteristics & Beech SOI & Spruce SOI & Oak SOI & Shallow soil SOI & Deep soil SOI \\
\hline Soil depth & -0.11 & -0.21 & 0.08 & -0.52 & -0.23 \\
\hline Stone fraction in top $50 \mathrm{~cm}$ & 0.34 & 0.26 & 0.06 & 0.34 & 0.01 \\
\hline Clay fraction in top $50 \mathrm{~cm}$ & 0.15 & -0.02 & 0.02 & -0.20 & 0.10 \\
\hline Mean root depth & 0.14 & 0.01 & 0.28 & -0.17 & -0.61 \\
\hline Site elevation & 0.42 & 0.57 & -0.01 & 0.41 & 0.26 \\
\hline Mean temperature & -0.12 & -0.48 & 0.19 & -0.42 & -0.29 \\
\hline Snow fraction & 0.12 & 0.42 & -0.24 & 0.49 & 0.32 \\
\hline Previous 50 days' precipitation & 0.22 & 0.25 & -0.25 & 0.28 & 0.05 \\
\hline Annual precipitation & 0.50 & 0.51 & 0.08 & 0.37 & 0.20 \\
\hline Summer 2015 precipitation - PET & 0.43 & 0.59 & 0.09 & 0.43 & 0.22 \\
\hline
\end{tabular}

isons of SOI across climatic, topographic, and edaphic gradients. Total annual precipitation and other climate metrics associated with water-balance surplus showed statistically significant, positive correlations with the SOI of xylem water and lysimeter soil water (Table S1). Thus, SOI variations in midsummer xylem water across Switzerland were not only a product of differences in distributions of species with distinct rooting habits. The cross-site trends in lysimeter waters mirrored those of xylem waters (both have stronger winter signatures in drier sites; Fig. 2 and Table 1); this suggests that the xylem water trend does not solely reflect differences in rooting habits, because there are also trends in lysimeter soil water seasonal origins. Jasechko et al. (2014) similarly observed that aquifers were disproportionately winter-sourced in areas with summer water deficits, probably because under those conditions more summer precipitation evaporates. SOI was also positively correlated with slope and elevation, possibly because these topographic variables co-vary with precipitation (Tables S1 and S2). Surprisingly, correlations between soil characteristics and SOI were weaker and inconsistent (Tables 1 and S1), suggesting that soil texture may be less important than climate in their control over the turnover of plant-available water.

Species differed in their water sources, as reflected by differences in their xylem water SOI. Spruce is considered to be shallow-rooted, with its roots mostly occurring in the top $25 \mathrm{~cm}$ (Schmid and Kazda, 2002), compared to beech and oak, whose roots are reported to mostly occur in the top $40 \mathrm{~cm}$ (Schmid and Kazda, 2002; Thomas and Hartmann, 1998). However, measurements from soil pits excavated in each site show that both maximum and mean rooting depths were broadly similar among beech, spruce, and oak, with mean depths usually ranging between 15 and $35 \mathrm{~cm}$ and maximum depths usually ranging between 50 and $120 \mathrm{~cm}$ (Fig. 4 and Fig. S2). Regardless of these observed similarities in rooting depths, the isotope data show that beech used significantly more winter precipitation than spruce, even within the same plots (mean SOI difference of $0.53, n=27$ sites, $p<0.001$ by paired $t$ test, Fig. 5a; similarly, oak SOI was 0.54 lower than spruce SOI in the one plot where they were paired). In contrast, oak and beech within the same plots used similar waters (mean SOI difference of $0.10, n=11$ sites, $p=0.13$ by paired $t$ test; Fig. 5b). In sites with lysimeters, the soil waters they sampled were significantly less winterlike than beech xylem waters (mean SOI of -0.20 versus $-0.90, n=16$ sites, $p<0.001$ by paired $t$ test; Fig. $5 c$ ), suggesting that beech roots accessed water sources that were deeper (e.g., saprolite) or more tightly held (e.g., fine pores). These frequently overlooked water sources may be important for storing winter precipitation and supplying summer transpiration (Rempe and Dietrich, 2018). In contrast, suction lysimeters generally sample a more mobile, less tightly held fraction of soil water (Brooks et al., 2010; Sprenger et al., 2016). Spruce, unlike beech, appear to use water that is more similar to this more mobile water; the SOI of spruce xylem water was statistically indistinguishable from lysimeter soil water at paired sites (mean SOI of -0.27 versus $-0.14, n=21$ sites, $p=0.13$ by paired $t$ test; Fig. $5 c$ ). Thus, spruce trees used fundamentally different water sources than the two broadleaf species, demonstrating niche partitioning in the rhizosphere across a wide range of soils and climates. Given that the spruce and beech trees had similar rooting depths but used different source waters (Fig. 4), we hypothesize that these species niche separations relate to their relative uptake of water from more vs. less conductive soil pores.

The SOI of xylem water reflects root access to water sources with different seasonal dynamics, implying vulnerability to different types of droughts. While deep roots are assumed to mitigate vulnerability to droughts (Ehleringer et al., 1991; West et al., 2012) by providing access to storages of past precipitation, this will not be the case where deeper substrates lack sufficient storage capacity or are not reliably recharged by infiltrating precipitation (Fan et al., 2017). Here, the data suggest that SOI variations are not solely a reflection of rooting depth differences because rooting depths (a) lacked a strong trend across sites (Fig. S2), (b) were sim- 

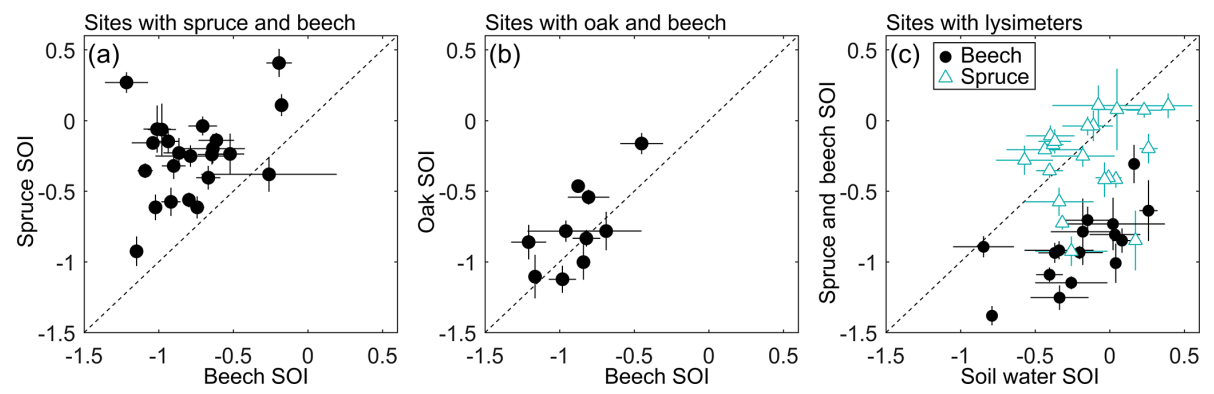

Figure 5. Pairwise comparisons of seasonal origin index values for sites where (a) spruce and beech are collocated, (b) oak and beech are collocated, and (c) trees and lysimeters are collocated. The 1:1 lines are plotted for reference, highlighting that (a) spruce used more summer-sourced water than beech, whereas (b) beech and oak used similar water supplies. Additionally, (c) spruce used water similar to lysimeter soil water, unlike beech. Symbols indicate site means with error bars representing 1 standard error of the mean, attributable to intra-site variability.

ilar among species (Fig. 4), and (c) were weakly correlated with SOI (Tables 1 and S1). Nonetheless, the xylem water with low SOI directly reflects access to storages that recharge in winter, regardless of whether those waters are deeper or more tightly held. Trees that use stored winter precipitation (e.g., beech and oak in drier regions; Fig. 6) may be less vulnerable to summer precipitation deficits but more reliant on the soil's capacity to store sufficient amounts of winter water through the growing season. As increasing temperatures result in longer growing seasons (Körner and Basler, 2010), winter water stores may become insufficient to sustain tree growth in regions with seasonal water deficits (Fig. S3). In contrast, midsummer xylem water with high SOI (e.g., spruce trees in central and southern Switzerland; Fig. 6) directly reflects access to storages with more rapid turnover, in which water from previous seasons has drained away or been displaced by summer precipitation. Spruce's greater use of summer rainfall may explain why it is more sensitive than beech to summer droughts (Brinkmann et al., 2016; Zang et al., 2014). Ultimately, further research is needed to clarify the extent to which seasonal origin signals are attributable to rooting habits versus water-transport processes. Understanding why these spatial and inter-species differences occur and whether they persist are key to understanding their implications for predicting forest vulnerability to droughts.

Beyond these hydrological and ecological insights, our findings have implications for the use of stable isotopes in climate science and ecophysiology, because variations in the seasonal origins of xylem water imply that plant tissue $\delta^{2} \mathrm{H}$ or $\delta^{18} \mathrm{O}$ (frequently used as climatic or ecophysiological proxies) may reflect different seasons in different species, individuals, sites, and years. The $\delta^{2} \mathrm{H}$ or $\delta^{18} \mathrm{O}$ signatures of plant tissue (e.g., cellulose and leaf waxes) reflect the initial $\delta^{2} \mathrm{H}$ or $\delta^{18} \mathrm{O}$ of the source water incorporated into plant tissue, as well as climatically and physiologically controlled fractionation effects (Barbour, 2007). In a variety of isotope applications, it is often useful to attribute the source water to summer rainfall (Lawrence and White, 1984) or mean an- nual precipitation (Helliker and Richter, 2008); however, we observed waters in trees that had neither a consistent summer signature nor a consistent mean annual signature (see Fig. S4). Although these xylem waters were sampled at one point in time, they document widespread temporal decoupling between precipitation inputs and plant water uptake. If, as these results suggest, seasonal origins vary systematically by species and across climatic gradients, accounting for these variations could aid in interpreting plant-tissue stable isotopes as environmental proxies.

Variations in SOI also convey information about how soils transport water. Only the wettest sites clearly demonstrated substantial transport of summer precipitation to the rhizosphere. Elsewhere, the summer rainfall apparently did not reach (or potentially bypassed) the relatively shallow depths that contained most of the fine roots (e.g., $15-40 \mathrm{~cm}$; Fig. 3), suggesting that infiltration was not a piston-flow process (e.g., translatory flow), as also previously argued by Brooks et al. (2010). Further evidence for the lack of translatory flow can be observed in the scarcity of soil waters (sampled by lysimeters or taken up by roots) with a strong summer signature (Fig. 2); this indicates that summer precipitation must either mix with or bypass the storage. Our findings differ from the ecohydrologic separation in a Mediterranean climate described by Brooks et al. (2010), in which infiltrating water refilled pore spaces when soils were dry and otherwise bypassed the rhizosphere when soils were wet. In contrast, our cross-site comparison indicates that recent precipitation refilled rhizosphere pore spaces more in wetter sites than in drier sites. The low SOI of xylem water in beech and oak trees implies that little summer precipitation traveled to their roots, likely because it either bypassed the soil matrix or was retained in near-surface soils before quickly returning to the atmosphere (e.g., by understory transpiration or evaporation of soil water and intercepted precipitation). A recent study (Brinkmann et al., 2018) focused on temporal variations in a single site and found that roughly $50 \%$ of tree water use came from summer precipitation, but this fraction 


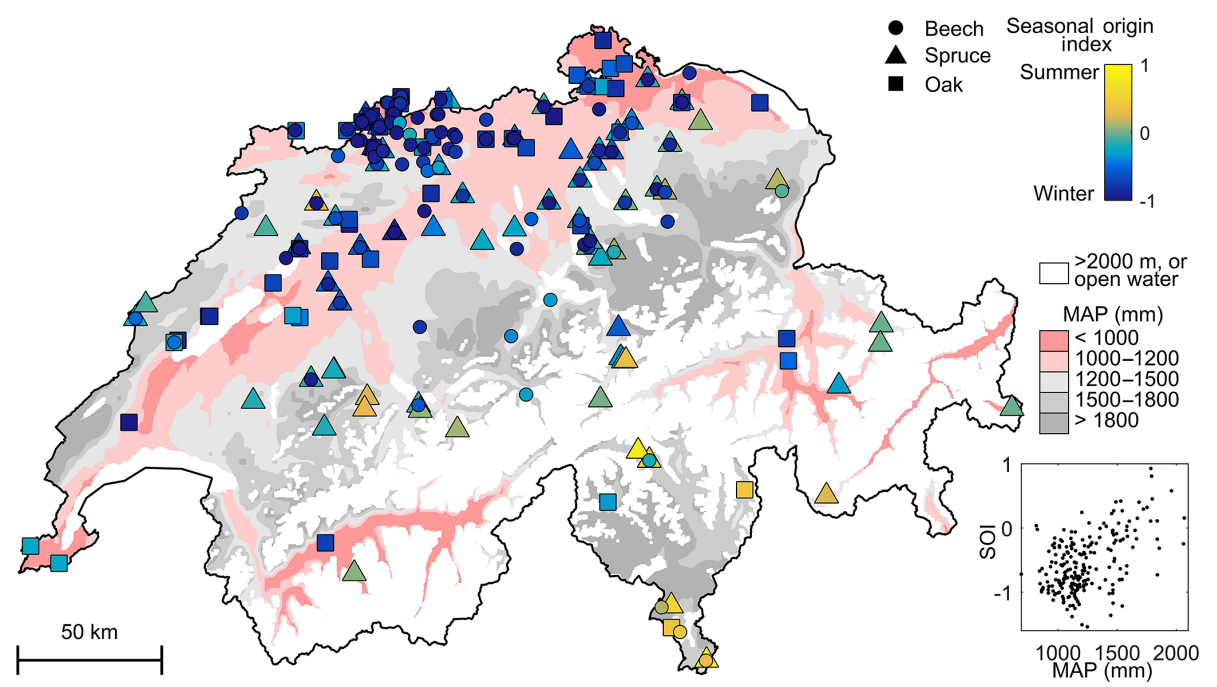

Figure 6. Variation in seasonal origins of tree xylem water with mean annual precipitation (MAP) across Switzerland. Open water and elevations > $2000 \mathrm{~m}$ a.s.l. are excluded. In all but the wettest regions, the seasonal origin index shows a predominance of winter precipitation in tree xylem.

varied throughout the growing season. Different insights are conveyed by our snapshot sample from over 900 trees across a network of diverse sites. They empirically show that the majority of midsummer tree xylem, and by extension rhizosphere soils, contain only small contributions from summer precipitation in midsummer. Regardless of these data reflecting a single snapshot, these measurements imply that the turnover of water (and thus flushing of solutes) in these trees' rooting zones must be remarkably small in summer.

Although SOI values do not precisely record water age, the widespread presence of winter precipitation in summer soils indicates that these waters often resided in soils for months with minimal mixing, suggesting that summer precipitation flows preferentially through those soils. We can explore these flow processes through a back-of-the-envelope calculation. Mean transit time can be calculated hydrometrically as storage divided by flux (also often referred to as mean turnover time). We conservatively estimate the storage above the rooting zone to be $10.5 \mathrm{~cm}$ of water (most roots are above $30 \mathrm{~cm}$, shown in Fig. 3, multiplied by the maximum field capacity of 0.35 ). We estimate the mean flux to the roots to be $1.36 \mathrm{~mm}$ per day, calculated as precipitation minus evaporation using the precipitation $(2.51 \mathrm{~mm}$ per day) and mean PET ( $4.6 \mathrm{~mm}$ per day) across the sites in the 50 days prior to sampling, and with evaporation assumed to be 0.25 of PET, which is conservative as an estimated fraction of evaporation over actual evapotranspiration in full-canopy forest (Schlesinger and Jasechko, 2014). Assuming steady-state conditions, this yields an estimated hydrometric mean transit time (or turnover time) of 77 days in summer (and it must be substantially shorter in spring or winter because PET is lower and precipitation rates are similar). If mean transit times are 77 days and soil water storages are composed of waters with undiluted, midwinter precipitation isotope values, then stored waters must be substantially older than the mean transit time. This contrast between storage ages and the mean transit time would suggest that soil water flows are neither well-mixed nor translatory and instead are preferential (sensu Berghuijs and Kirchner, 2017), although it remains unclear how fully roots sample and reflect the age of soil water storage. Indeed, these root surveys are coarse characterizations, and some deeper (and potentially overlooked) roots could transport a disproportionately large fraction of water. Regardless, the empirical insights shown here - specifically, trends in the seasonal origins of water in soils across climates, and differences in the use of recent precipitation versus older stored precipitation among species may find application in better parameterizations of plant uptake of water from dynamic storages in gridded hydrological or ecological models.

More broadly, the analytical framework introduced here provides a new tool for applying stable isotope data to explore a wide variety of ecological and hydrological processes. Here, the seasonal origin analysis aids in describing plant-soil-water interactions and how they vary across landscapes; specifically, examining the seasonal origin of tree water revealed (1) the consistent inter-species differences in rhizosphere water niches, (2) the long residence times of rootzone soil moisture in summer, and (3) the need to consider the overexpression of different seasons' precipitation when interpreting plant-tissue isotopes. We suspect that insights may also be revealed through applying this seasonal origin index analysis to groundwater (sensu Jasechko et al., 2014), stream water, or even plant and animal tissues. 


\section{Summary and conclusions}

The seasonal origins of precipitation used by trees, which reflect the interplay between infiltration dynamics and root distributions, have not previously been systematically investigated. We used a spatially extensive snapshot sample of xylem water from Swiss forest plots to quantify the seasonal origins of water used by trees in midsummer. Xylem waters in 918 trees from 182 sites (and soil lysimeter water from a subset of these sites) were sampled and analyzed for $\delta^{18} \mathrm{O}$ and $\delta^{2} \mathrm{H}$ by a single team using consistent methods (thereby avoiding many uncertainties that are common to meta-analyses). By applying a new index that characterizes the occurrence of summer versus winter precipitation in these xylem samples, we show that trees mostly used winter precipitation in midsummer in all but the wettest regions of Switzerland (Fig. 1). Summer precipitation isotope signatures were uncommon in shallow soils, deep soils, and tree xylem (Fig. 2), suggesting that infiltrating precipitation does not simply displace stored soil waters. There was consistent partitioning in the water sources used by different species (Fig. 3): beech and oak almost entirely used winter precipitation, whereas spruce used more mixed sources that were isotopically similar to the water extracted by suction lysimeters (presumably from more conductive pores). The widespread prevalence of winter precipitation in midsummer tree xylem suggests that (a) the turnover of water (and thus flushing of solutes) in these trees' rooting zones must be remarkably small in summer and (b) plant-tissue isotope proxies may not consistently capture summer climate signals. These findings conflict with common assumptions on tree water use and provide empirical support for developing more realistic representations of root-soil-water interactions.

Data availability. The data that support the findings of this study are available in the Supplement. We acknowledge data contributions by International Atomic Energy Association and GNIP contributors as well as Swiss, German, and Austrian federal monitoring agencies (Swiss Federal Office of the Environment (FOEN) and its NAQUA program, MeteoSwiss, Austrian Network of Isotopes in Precipitation, Austrian Zentralanstalt für Meteorologie und Geodynamik, and Deutscher Wetterdienst).

Supplement. The supplement related to this article is available online at: https://doi.org/10.5194/hess-23-1199-2019-supplement.

Author contributions. STA conceived and executed the analysis, with input from GRG and JWK. STA, JWK, and GRG wrote the paper. SB, GGR, and RTWS initiated the project and coordinated the 2015 field and lab work. SB leads the long-term measurement network.
Competing interests. The authors declare that they have no conflict of interest.

Acknowledgements. We thank Nadine Engbersen, Clara Romero, Lola Schmid, and the Institute for Applied Plant Biology team for assistance with sample collection and processing; Wouter Berghuijs and Julia Knapp for comments on the manuscript; and Wouter Berghuijs and Paolo Benettin for many useful discussions during the writing process. We thank two anonymous reviewers and Editor Markus Weiler for their helpful feedback. The forest departments of the cantons AG, BE, BL, BS, GR, SO, TG, ZH, and $\mathrm{ZG}$, as well as the environmental offices of Central Switzerland, funded the tree sampling. This project was funded by a Swiss Federal Office of the Environment agreement with Gregory R. Goldsmith and James W. Kirchner. Gregory R. Goldsmith was supported by funding from the European Commission's Seventh Framework Programme (FP7/2007-2013) under grant agreement number 290605 (COFUND: PSI-FELLOW) while at the Paul Scherrer Institute.

Edited by: Markus Weiler

Reviewed by: two anonymous referees

\section{References}

Allen, S. T., Kirchner, J. W., and Goldsmith, G. R.: Predicting spatial patterns in precipitation isotope $(\delta 2 \mathrm{H}$ and $\delta 18 \mathrm{O})$ seasonality using sinusoidal isoscapes, Geophys. Res. Lett., 45, 4859-4868, https://doi.org/10.1029/2018GL077458, 2018.

Barbour, M. M.: Stable oxygen isotope composition of plant tissue: a review, Funct. Plant Biol., 34, 83-94, https://doi.org/10.1071/FP06228, 2007.

Benettin, P., Volkmann, T. H. M., von Freyberg, J., Frentress, J., Penna, D., Dawson, T. E., and Kirchner, J. W.: Effects of climatic seasonality on the isotopic composition of evaporating soil waters, Hydrol. Earth Syst. Sci., 22, 2881-2890, https://doi.org/10.5194/hess-22-2881-2018, 2018.

Berghuijs Wouter R. and Kirchner, J. W.: The relationship between contrasting ages of groundwater and streamflow, Geophys. Res. Lett., 44, 8925-8935, https://doi.org/10.1002/2017GL074962, 2017.

Beven, K. and Germann, P.: Macropores and water flow in soils, Water Resour. Res., 18, 1311-1325, https://doi.org/10.1029/WR018i005p01311, 1982.

Botter, G., Bertuzzo, E., and Rinaldo, A.. Catchment residence and travel time distributions: The master equation, Geophys. Res. Lett., 38, L11403, https://doi.org/10.1029/2011GL047666, 2011.

Bowen, G. J., Putman, A., Brooks, J. R., Bowling, D. R., Oerter, E. J., and Good, S. P.: Inferring the source of evaporated waters using stable $\mathrm{H}$ and $\mathrm{O}$ isotopes, Oecologia, 187, 1025-1039, https://doi.org/10.1007/s00442-018-4192-5, 2018.

Braun, S., Rihm, B., Schindler, C., and Flückiger, W.: Growth of Mature Beech in Relation to Ozone and Nitrogen Deposition: an Epidemiological Approach, Water Air Soil Pollut., 116, 357364, https://doi.org/10.1023/A:1005209831728, 1999.

Braun, S., Schindler, C., and Rihm, B.: Growth trends of beech and Norway spruce in Switzerland: The role of nitrogen deposition, 
ozone, mineral nutrition and climate, Sci. Total Environ., 599600, 637-646, https://doi.org/10.1016/j.scitotenv.2017.04.230, 2017.

Brinkmann, N., Eugster, W., Zweifel, R., Buchmann, N., and Kahmen, A.: Temperate tree species show identical response in tree water deficit but different sensitivities in sap flow to summer soil drying, Tree Physiol., 36, 1508-1519, https://doi.org/10.1093/treephys/tpw062, 2016.

Brinkmann, N., Seeger, S., Weiler, M., Buchmann, N., Eugster, W., and Kahmen, A.: Employing stable isotopes to determine the residence times of soil water and the temporal origin of water taken up by Fagus sylvatica and Picea abies in a temperate forest, New Phytol., 219, 1300-1313, https://doi.org/10.1111/nph.15255, 2018.

Brooks, J., Barnard, H. R., Coulombe, R., and McDonnell, J. J.: Ecohydrologic separation of water between trees and streams in a Mediterranean climate, Nature Geosci., 3, 100-104, https://doi.org/10.1038/ngeo722, 2010.

Dubbert, M., Caldeira, M. C., Dubbert, D., and Werner, C.: A poolweighted perspective on the two-water-worlds hypothesis, New Phytol., https://doi.org/10.1111/nph.15670, in press, 2019.

Ehleringer, J. R., Phillips, S. L., Schuster, W. S. F., and Sandquist, D. R.: Differential utilization of summer rains by desert plants, Oecologia, 88, 430-434, https://doi.org/10.1007/BF00317589, 1991.

Ellsworth, P. Z. and Williams, D. G.: Hydrogen isotope fractionation during water uptake by woody xerophytes, Plant Soil, 291, 93-107, https://doi.org/10.1007/s11104-006-9177-1, 2007.

Evaristo, J., Jasechko, S., and McDonnell, J. J.: Global separation of plant transpiration from groundwater and streamflow, Nature, 525, 91-94, https://doi.org/10.1038/nature14983, 2015.

Fan, Y., Miguez-Macho, G., Jobbágy, E. G., Jackson, R. B., and Otero-Casal, C.: Hydrologic regulation of plant rooting depth, P. Natl. Acad. Sci., 114, 10572-10577, https://doi.org/10.1073/pnas.1712381114, 2017.

German BGR: Bodenkundliche Kartieranleitung, Bundesanstalt für Geowissenschaften und Rohstoffe (BGR) und den Geologischen Landesämtern in der Bundesrepublik Deutschland, Hannover, 2005.

Goldsmith, G. R., Allen, S. T., Braun, S., Engbersen, N., Gonzalez-Quijano, C. R., Kirchner, J. W., and Siegwolf, R. T. W.: Spatial variation in throughfall, soil, and plant water isotopes in a temperate forest, Ecohydrology, e2059, https://doi.org/10.1002/eco.2059, 2019.

Good, S. P., Noone, D., and Bowen, G.: Hydrologic connectivity constrains partitioning of global terrestrial water fluxes, Science, 349, 175-177, https://doi.org/10.1126/science.aaa5931, 2015.

Grossmann, J. and Udluft, P.: The extraction of soil water by the suction-cup method: a review, J. Soil Sci., 42, 83-93, 1991.

Halder, J., Terzer, S., Wassenaar, L. I., Araguás-Araguás, L. J., and Aggarwal, P. K.: The Global Network of Isotopes in Rivers (GNIR): integration of water isotopes in watershed observation and riverine research, Hydrol. Earth Syst. Sci., 19, 3419-3431, https://doi.org/10.5194/hess-19-3419-2015, 2015.

Helliker, B. R. and Richter, S. L.: Subtropical to boreal convergence of tree-leaf temperatures, Nature, 454, 511-514, https://doi.org/10.1038/nature07031, 2008.

Jasechko, S., Birks, S. J., Gleeson, T., Wada, Y., Fawcett, P. J., Sharp, Z. D., McDonnell, J. J., and Welker, J.
M.: The pronounced seasonality of global groundwater recharge, Water Resour. Res., 50, 8845-8867, https://doi.org/10.1002/2014WR015809, 2014.

Javaux, M., Rothfuss, Y., Vanderborght, J., Vereecken, H., and Brüggemann, N.: Isotopic composition of plant water sources, Nature, 536, E1-E3, https://doi.org/10.1038/nature18946, 2016.

Körner, C. and Basler, D.: Phenology Under Global Warming, Science, 327, 1461-1462, https://doi.org/10.1126/science.1186473, 2010.

Lawes, J. B., Gilbert, J. H., and Warington, R.: On the amount and composition of the rain and drainage water collected at Rothamsted, Williams Clowes and Sons, London, UK, 1882.

Lawrence, D. M., Oleson, K. W., Flanner, M. G., Thornton, P. E., Swenson, S. C., Lawrence Peter, J., Zeng, X., Yang, Z., Levis, S., Sakaguchi, K., Bonan, G. B., and Slater, A. G.: Parameterization improvements and functional and structural advances in Version 4 of the Community Land Model, J. Adv. Model. Earth Syst., 3, M03001, https://doi.org/10.1029/2011MS00045, 2011.

Lawrence, J. R. and White, J. W. C.: Growing season precipitation from D/H ratios of Eastern White Pine, Nature, 311, 558-560, https://doi.org/10.1038/311558a0, 1984.

Meißner, M., Köhler, M., Schwendenmann, L., Hölscher, D., and Dyckmans, J.: Soil water uptake by trees using water stable isotopes $(\delta 2 \mathrm{H}$ and $\delta 18 \mathrm{O})$ - a method test regarding soil moisture, texture and carbonate, Plant Soil, 376, 327-335, https://doi.org/10.1007/s11104-013-1970-z, 2014.

Mueller, M. H., Alaoui, A., Kuells, C., Leistert, H., Meusburger, K., Stumpp, C., Weiler, M., and Alewell, C.: Tracking water pathways in steep hillslopes by $\delta 18 \mathrm{O}$ depth profiles of soil water, J. Hydrol., 519, 340-352, https://doi.org/10.1016/j.jhydrol.2014.07.031, 2014.

Newberry, S. L., Nelson, D. B., and Kahmen, A.: Cryogenic vacuum artifacts do not affect plant water-uptake studies using stable isotope analysis, Ecohydrology, 10, e1892, https://doi.org/10.1002/eco.1892, 2017.

Oerter, E., Finstad, K., Schaefer, J., Goldsmith, G. R., Dawson, T., and Amundson, R.: Oxygen isotope fractionation effects in soil water via interaction with cations $(\mathrm{Mg}, \mathrm{Ca}, \mathrm{K}, \mathrm{Na})$ adsorbed to phyllosilicate clay minerals, J. Hydrol., 515, 1-9, https://doi.org/10.1016/j.jhydrol.2014.04.029, 2014.

O'Green, A. T.: Soil water dynamics, Nature Education Knowledge, 3, 12, 2012.

Orlowski, N., Breuer, L., Angeli, N., Boeckx, P., Brumbt, C., Cook, C. S., Dubbert, M., Dyckmans, J., Gallagher, B., Gralher, B., Herbstritt, B., Hervé-Fernández, P., Hissler, C., Koeniger, P., Legout, A., Macdonald, C. J., Oyarzún, C., Redelstein, R., Seidler, C., Siegwolf, R., Stumpp, C., Thomsen, S., Weiler, M., Werner, C., and McDonnell, J. J.: Inter-laboratory comparison of cryogenic water extraction systems for stable isotope analysis of soil water, Hydrol. Earth Syst. Sci., 22, 3619-3637, https://doi.org/10.5194/hess-22-3619-2018, 2018.

Penna, D., Hopp, L., Scandellari, F., Allen, S. T., Benettin, P., Beyer, M., Geris, J., Klaus, J., Marshall, J. D., Schwendenmann, L., Volkmann, T. H. M., von Freyberg, J., Amin, A., Ceperley, N., Engel, M., Frentress, J., Giambastiani, Y., McDonnell, J. J., Zuecco, G., Llorens, P., Siegwolf, R. T. W., Dawson, T. E., and Kirchner, J. W.: Ideas and perspectives: Tracing terrestrial ecosystem water fluxes using hydrogen and oxygen stable isotopes - challenges and opportunities from an 
interdisciplinary perspective, Biogeosciences, 15, 6399-6415, https://doi.org/10.5194/bg-15-6399-2018, 2018.

Rempe, D. M. and Dietrich, W. E.: Direct observations of rock moisture, a hidden component of the hydrologic cycle, P. Natl. Acad. Sci., 115, 2664-2669, https://doi.org/10.1073/pnas.1800141115, 2018.

Schlesinger, W. H. and Jasechko, S.: Transpiration in the global water cycle, Agr. Forest Meteorol., 189-190, 115-117, https://doi.org/10.1016/j.agrformet.2014.01.011, 2014.

Schmid, I. and Kazda, M.: Root distribution of Norway spruce in monospecific and mixed stands on different soils, Forest Ecol. Manag., 159, 37-47, https://doi.org/10.1016/S03781127(01)00708-3, 2002.

Sprenger, M., Leistert, H., Gimbel, K., and Weiler, M.: Illuminating hydrological processes at the soil-vegetation-atmosphere interface with water stable isotopes, Rev. Geophys., 54, 2015RG000515, https://doi.org/10.1002/2015RG000515, $2016 \mathrm{a}$.

Sprenger, M., Seeger, S., Blume, T., and Weiler, M.: Travel times in the vadose zone: Variability in space and time, Water Resour. Res., 52, 5727-5754, https://doi.org/10.1002/2015WR018077, $2016 b$.

Stewart, J. B., Moran, C. J., and Wood, J. T.: Macropore sheath: quantification of plant root and soil macropore association, Plant and Soil, 211, 59-67, https://doi.org/10.1023/A:1004405422847, 1999.

Thomas, F. M. and Hartmann, G.: Tree rooting patterns and soil water relations of healthy and damaged stands of mature oak (Quercus robur L. and Quercus petraea [Matt.] Liebl.), Plant and Soil, 203, 145-158, https://doi.org/10.1023/A:1004305410905, 1998.

Tinker, P. B.: Roots and water: transport of water to plant roots in soil, Philos. T. Roy. Soc. Lond. B, 273, 445-461, https://doi.org/10.1098/rstb.1976.0024, 1976.

Treydte, K., Boda, S., Graf Pannatier, E., Fonti, P., Frank, D., Ullrich, B., Saurer, M., Siegwolf, R., Battipaglia, G., Werner, W., and Gessler, A.: Seasonal transfer of oxygen isotopes from precipitation and soil to the tree ring: source water versus needle water enrichment, New Phytol., 202, 772-783, https://doi.org/10.1111/nph.12741, 2014.
Vachon, R. W., White, J. W. C., Gutmann, E., and Welker, J. M.: Amount-weighted annual isotopic $(\delta 18 \mathrm{O})$ values are affected by the seasonality of precipitation: A sensitivity study, Geophys. Res. Lett., 34, L21707, https://doi.org/10.1029/2007GL030547, 2007.

Weihermüller, L., Kasteel, R., Vanderborght, J., Pütz, T., and Vereecken, H. Soilwater extraction with a suction cup, Vadose Zone J., 4, 899-907, https://doi.org/10.2136/vzj2004.0156, 2005.

West, A. G., Patrickson, S. J., and Ehleringer, J. R.: Water extraction times for plant and soil materials used in stable isotope analysis, Rapid Communications in Mass Spectrometry, 20, 1317-1321, https://doi.org/10.1002/rcm.2456, 2006.

West, A. G., Dawson, T. E., February, E. C., Midgley, G. F., Bond, W. J., and Aston, T. L.: Diverse functional responses to drought in a Mediterranean-type shrubland in South Africa, New Phytol., 195, 396-407, https://doi.org/10.1111/j.14698137.2012.04170.x, 2012.

Wigmosta, M. S., Vail, L. W., and Lettenmaier, D. P.: A distributed hydrology-vegetation model for complex terrain, Water Resour. Res., 30, 1665-1679, https://doi.org/10.1029/94WR00436, 1994.

Zang, C., Hartl-Meier, C., Dittmar, C., Rothe, A., and Menzel, A.: Patterns of drought tolerance in major European temperate forest trees: climatic drivers and levels of variability, Glob. Change Biol., 20, 3767-3779, https://doi.org/10.1111/gcb.12637, 2014.

Zhao, L., Wang, L., Cernusak, L. A., Liu, X., Xiao, H., Zhou, M. and Zhang, S.: Significant Difference in Hydrogen Isotope Composition Between Xylem and Tissue Water in Populus Euphratica, Plant, Cell \& Environment, 39(8), 1848-1857, https://doi.org/10.1111/pce.12753, 2016. 